\title{
Letrozole in the extended adjuvant setting: MA.17
}

\author{
Paul E. Goss
}

Received: 3 January 2007 / Accepted: 17 July 2007

(C) Springer Science+Business Media, LLC 2007

\begin{abstract}
Relapse after completing adjuvant tamoxifen therapy is a persistent threat for women with hormoneresponsive breast cancer. Third-generation aromatase inhibitors, such as letrozole, provide a new option for extended adjuvant hormonal therapy after 5 years of tamoxifen. MA.17 was conducted to determine whether letrozole improves outcome after discontinuation of tamoxifen. Postmenopausal women with hormone receptor-positive breast cancer $(\mathrm{N}=5,187)$ were randomized to letrozole $2.5 \mathrm{mg}$ or placebo once daily for 5 years. At a median follow-up of 30 months, letrozole significantly improved disease-free survival (DFS; $P<0.001$ ), the primary end point, compared with placebo (hazard ratio [HR] for recurrence or contralateral breast cancer 0.58 ; $95 \%$ confidence interval [CI] $0.45,0.76] P<0.001)$. Furthermore, letrozole significantly improved distant DFS $(\mathrm{HR}=0.60 ; 95 \%$ CI $0.43,0.84 ; P=0.002)$ and, in women with node-positive tumors, overall survival $(\mathrm{HR}=0.61$; 95\% CI 0.38, 0.98; $P=0.04)$. Clinical benefits, including an overall survival advantage, were also seen in women who crossed over from placebo to letrozole after unblinding, indicating that tumors remain sensitive to hormone therapy despite a prolonged period since discontinuation of tamoxifen. The efficacy and safety of letrozole therapy beyond 5 years is being assessed in a re-randomization study, following the emergence of new data suggesting that clinical benefit correlates with the duration of letrozole. MA.17 showed that letrozole is extremely well-tolerated relative to placebo. Letrozole should be considered for all women completing tamoxifen; new results from the post-
\end{abstract}

P. E. Goss $(\square)$

Massachusetts General Hospital Cancer Center, 55 Fruit Street, Cox Bldg., Room 640, Boston, MA 02114, USA

e-mail:pgoss@partners.org unblinding analysis suggest that letrozole treatment should also be considered for all disease-free women for periods up to 5 years following completion of adjuvant tamoxifen.

Keywords Aromatase inhibitors - Breast cancer . Letrozole $\cdot$ MA.17 - Tamoxifen

\section{Introduction and rationale}

There is a persistent risk of breast cancer recurrence following primary treatment [1-3]. Initially, patients with hormone receptor-positive (HR+) breast tumors have a lower risk of recurrence than those with HR- tumors, but with longer follow-up, the opposite may be the case [3, 4]. For example, Saphner showed that the significantly higher hazard of recurrence in HR- versus HR+ patients in the time period $0-12$ years $(P<0.00001)$ could be explained by the higher risk of recurrence in years $0-5$ for HRpatients $(P<0.0001)$. However, between years 3 and 4 , the hazard of recurrence for $\mathrm{HR}-$ and $\mathrm{HR}+$ patients crossed, and beyond 5 years was actually higher for HR+ patients $(P=0.00002)$ [4]. These data clearly indicate the need for continuous hormonal treatment for women with HR+ tumors.

The benefits of adjuvant hormonal treatment with tamoxifen were first demonstrated in the National Surgical Adjuvant Breast and Bowel Project (NSABP) B-14 trial [5]. This large randomized, double-blind, placebo-controlled trial involving patients with node-negative, $\mathrm{HR}+$ breast cancer demonstrated a significant prolongation of disease-free survival (DFS) among women treated with tamoxifen for 5 years, as compared with those receiving placebo. Updated results with longer follow-up demonstrated that the 5-year benefit in DFS with tamoxifen persisted through at least 10 years of follow- 
up, and a statistically significant survival benefit was also observed [6]. However, since the optimal duration of tamoxifen therapy was not known, patients who had completed 5 years of tamoxifen therapy and were disease-free were re-randomized to receive placebo or tamoxifen. Results published with a follow-up of 7 years after reassignment demonstrated a disadvantage in patients who continued tamoxifen compared with those who discontinued: DFS was 78 vs. $82 \%$, respectively $(P=0.03)$, and overall survival (OS) was 91 vs. $94 \%(P=0.07)$. Thus, extending tamoxifen treatment beyond 5 years was not deemed beneficial [7] nor recommended [8] when the MA.17 trial was initiated.

While clearly in the best interest of patients, discontinuation of tamoxifen after 5 years creates a therapeutic dilemma because of the persistent risk of breast cancer recurrence. Relapse or appearance of new tumors after completion of tamoxifen therapy is relatively common in patients with HR+ tumors $[1,2,4,7]$. The Oxford metaanalysis found that more than half of breast cancer recurrences and two thirds of breast cancer deaths occur after 5 years of adjuvant tamoxifen [3]. In the NSABP B-14 trial, the average annual rate of breast cancer recurrences was 8.9 per 1,000 patients who discontinued tamoxifen at 5 years [7]. Patients in whom tamoxifen is discontinued therefore require an alternative treatment option to provide continuing protection from recurrence.

The loss of efficacy seen with long-term tamoxifen therapy may result from the emergence of a hormoneindependent tumor phenotype $[9,10]$ or the induction of hypersensitivity to estradiol $[11,12]$. Tamoxifen is thought to be more susceptible than aromatase inhibitors (AIs) to this adaptive change because of its intrinsic agonist properties [12]. Furthermore, data from the NSABP B-14 trial suggest that residual tumor cells may become tamoxifenresistant, and that continued use of tamoxifen might in fact stimulate their proliferation $[6,13]$.

The development of highly potent and selective thirdgeneration AIs provided a new hormone therapy option for patients with HR+ breast cancer [14-16]. It is suggested in independent studies that Letrozole $\left(\right.$ Femara ${ }^{\circledR}$ ) is the most potent of the AIs as determined by in vitro assays [17] and clinical studies of total body aromatization [18]. A recent study has demonstrated that the more complete inhibition of aromatase achieved by $2.5 \mathrm{mg}$ of letrozole than by $1 \mathrm{mg}$ of anastrozole results in a greater degree of suppression of estradiol [19]. The clinical efficacy of letrozole was initially demonstrated in patients with $\mathrm{HR}+$ metastatic breast cancer. In this setting, first-line therapy with letrozole was shown to significantly improve outcome compared with tamoxifen therapy $[20,21]$. While OS was not significantly improved (34 vs. 30 months, respectively), an exploratory analysis of the patients that did not cross over showed a longer survival benefit for letrozole-treated patients
(35 vs. 20 months) [22]. Second-line therapy with letrozole has also demonstrated significant clinical benefits in patients with $\mathrm{HR}+$ metastatic breast cancer in whom tamoxifen has failed [23], and in one randomized trial demonstrated a significantly higher response rate than anastrozole in this population [24].

Data from in vivo models using MCF-7 cells transfected with the aromatase gene have shown that letrozole is more effective than tamoxifen and devoid of the agonist action observed with the selective estrogen receptor modulator $[25,26]$. Although the mechanisms of estrogen blockade are different for letrozole and tamoxifen, combining the two agents did not increase antitumor activity in the MCF7 xenograft model [25]. The authors proposed that sequential administration of tamoxifen and letrozole would be a more effective strategy [25]. This hypothesis was recently confirmed in vivo [27]. Using the MCF-7 model, it was demonstrated that tumors progressing on tamoxifen responded to second-line letrozole therapy, but tumors that progressed on letrozole did not respond to second-line treatment with tamoxifen or fulvestrant [27].

The evident need to continue hormone therapy after discontinuation of tamoxifen in patients with HR+ primary breast cancer and the potential efficacy of AIs in tumors resistant to tamoxifen provided the rationale for testing adjuvant letrozole after 5 years of tamoxifen. This paper reviews the key results from the landmark MA.17 trial $[28,29]$ and discusses the advantages of letrozole treatment after the recommended 5 years of tamoxifen therapy have been completed. To date, letrozoleistheonly AIapprovedintheUnitedStatesandEurope forextended adjuvant therapy.

\section{Trial design and patients}

MA.17 was a phase III, randomized, double-blind, placebocontrolled trial of letrozole as extended adjuvant therapy in postmenopausal women with primary breast cancer who had completed approximately 5 years of adjuvant tamoxifen therapy $[28,29]$. The aim of the trial was to determine whether letrozole improves outcome after the discontinuation of adjuvant tamoxifen therapy. The MA.17 trial was led by the National Cancer Institute of Canada Clinical Trials Group and included the North American Breast Intergroup and the Breast International Group. Institutional review boards of participating institutions approved the study protocol, and all patients gave written informed consent.

\section{Patient population}

The trial enrolled 5,187 postmenopausal women with earlystage breast cancer in whom 5 years of tamoxifen (range 4.5- 
6 years) therapy had been completed less than 3 months before enrollment. Eligible women had to have histologically confirmed, HR+ primary breast cancer. HR+ tumors were defined as estrogen receptor-positive (ER+) or progesterone receptor-positive (PgR+) as determined by a level of $10 \mathrm{fmol} /$ $\mathrm{mg}$ of protein or a positive immunohistochemical analysis. Women were defined as being postmenopausal if they were aged at least 50 years at the start of adjuvant tamoxifen therapy, were $<50$ years of age at the start of tamoxifen therapy but postmenopausal at the initiation of tamoxifen therapy, were $<50$ years at the start of tamoxifen therapy but had undergone bilateral oophorectomy, were premenopausal and $<50$ years at the start of tamoxifen therapy but became amenorrheic during chemotherapy or treatment with tamoxifen, or were any age but had postmenopausal levels of luteinising hormone or follicle-stimulating hormone prior to the study. All women had a good performance status and life expectancy of at least 5 years.

\section{Randomized trial design}

Eligible women were randomly assigned to receive treatment with letrozole $(2.5 \mathrm{mg})$ or placebo orally daily for 5 years (see Fig. 1). Women were stratified according to the tumor HR status (positive or unknown), lymph-node status (negative, positive, or unknown), and receipt or nonreceipt of previous adjuvant chemotherapy. Exploratory sub-analyses were based on these stratification factors and two additional covariates (criteria for the definition of postmenopausal status at the start of tamoxifen treatment and duration of tamoxifen treatment).

End points and rules for interim analyses

The primary end point of the trial was DFS, defined as the time from randomization to the earliest recurrence of the

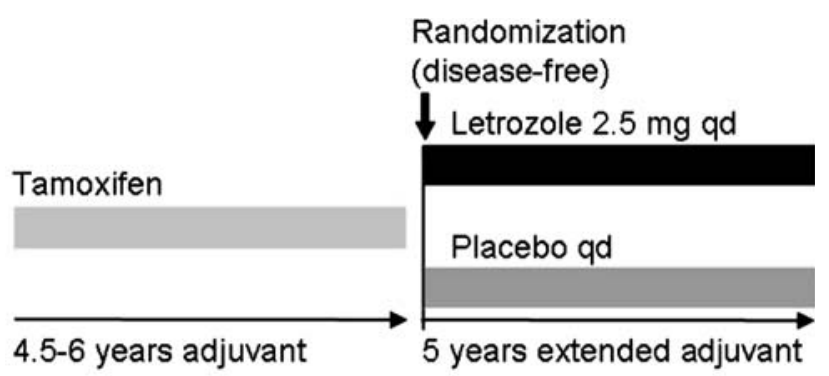

Primary end point: disease-free survival Secondary end points: overall survival/safety Substudies: quality of life, bone mineral density, bone markers, lipid profile

Fig. 1 MA.17 randomized trial design primary disease (in the breast, chest wall, or nodal or distant metastatic sites) or the development of a new primary breast cancer in the contralateral breast. Secondary cancer and death without a recurrence or a diagnosis of contralateral breast cancer were not included as events. The trial was powered to detect a $2.5 \%$ improvement in 4-year DFS with letrozole (from 88 to $90.5 \%$ ). Two interim analyses were scheduled, and stopping rules were specified a priori for interim monitoring [30].

The secondary efficacy end points of the trial were OS (defined as the time from randomization to death from any cause), annual incidence rate of contralateral breast cancer, long-term safety and tolerability, and overall and menopause-specific quality of life (QOL). In addition, distant DFS (DDFS), defined as the time from random assignment until the first observation of distant metastasis, was included as a secondary efficacy end point in the final analysis [29].

QOL and long-term safety were assessed as secondary end points [31]. Adverse events were graded according to the Common Toxicity Criteria of the National Cancer Institute (version 2.0). QOL was assessed with the Medical Outcomes Study 36-Item Short Form General Health Survey (SF-36) and the Menopause-Specific Quality of Life questionnaire [32, 33]. The effects of letrozole on lipid profile and bone mineral density (BMD) were assessed annually in companion studies to MA.17 [34, 35].

\section{Efficacy of letrozole as extended adjuvant therapy}

A total of 5,187 patients were randomized to either letrozole $(n=2,593)$ or placebo $(n=2,594)$. Because of noncompliance, 10 patients in the letrozole and seven in the placebo arm were excluded from all analyses, leaving 5,170 patients (2,583 on letrozole and 2,587 on placebo) in the time to event analysis (50 patients deemed ineligible for several reasons and 33 with major protocol violations were included in the analysis). The final safety analysis excluded 21 patients who never received study medication, yielding a final safety population of 5,149 patients, 2,572 receiving letrozole and 2,577 receiving placebo [29]. Based on the $43 \%$ reduction in recurrence risk $(P=0.00008)$ with letrozole seen in the first interim analysis at 2.4 years' median follow-up [28], the data and safety monitoring committee recommended that the MA.17 trial be discontinued early, and the participants were informed of the results. The trial was unblinded in October 2003, and patients on placebo were given the opportunity to switch to letrozole. Updated efficacy results after a median follow-up of 30 months confirmed the significant clinical benefits of letrozole as extended adjuvant therapy [29]. The updated trial results and recent additional efficacy analyses of MA.17 are summarized below. 
Letrozole significantly improves outcome

At 30 months' follow-up, letrozole significantly improved DFS, the primary end point, compared with placebo (see Fig. 2) [29]. The 4-DFS for patients receiving letrozole was $94.4 \%$, compared with $89.8 \%$ for patients receiving placebo. The hazard ratio for recurrence or contralateral breast cancer was 0.58 (95\% confidence interval [CI] 0.45, 0.76; $P \leq 0.76$ ), representing a $42 \%$ reduction in risk for letrozole relative to placebo. The updated analysis also showed that letrozole produced a statistically significant improvement in DDFS (hazard ratio $=0.60 ; 95 \%$ CI 0.43 , $0.84 ; P=0.002$ ), which may be regarded as a more meaningful end point than overall DFS; women with distant metastases inevitably die of breast cancer, and an improvement in DDFS may therefore translate into longer overall survival [36, 37]. Letrozole treatment non-significantly prolonged time to contralateral breast cancer incidence, resulting in a $37.5 \%$ relative risk reduction compared with placebo [29].

The prospectively planned subgroup analysis showed that letrozole significantly improved DFS in all patients, irrespective of nodal status. The reduction in risk of recurrence in node-positive tumors was $39 \%$ (hazard ratio $=0.61 ; 95 \%$ CI $0.45,0.84)$, and $55 \%$ in those with node-negative tumors (hazard ratio $=0.45$; $95 \%$ CI $0.27,0.73)$. While OS was not significantly improved (hazard ratio $=0.82 ; 95 \%$ CI $0.57,1.19$; $P=0.3$ ), letrozole significantly improved OS in patients with node-positive tumors (hazard ratio $=0.61$; 95\% CI 0.38, 0.98; $P=0.04$ ) (see Fig. 3), and this was the first survival advantage demonstrated by an AI in early breast cancer.

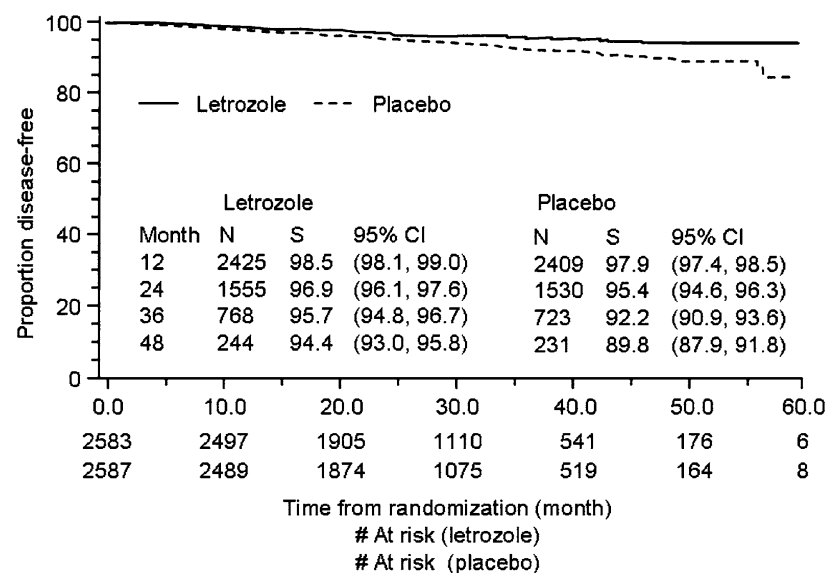

Fig. 2 Kaplan-Meier curves for disease-free survival in the updated analysis of MA.17. N, number at risk; S, survival percent, with $95 \%$ confidence intervals (CIs) in parentheses. Reprinted from ref. [29] with permission

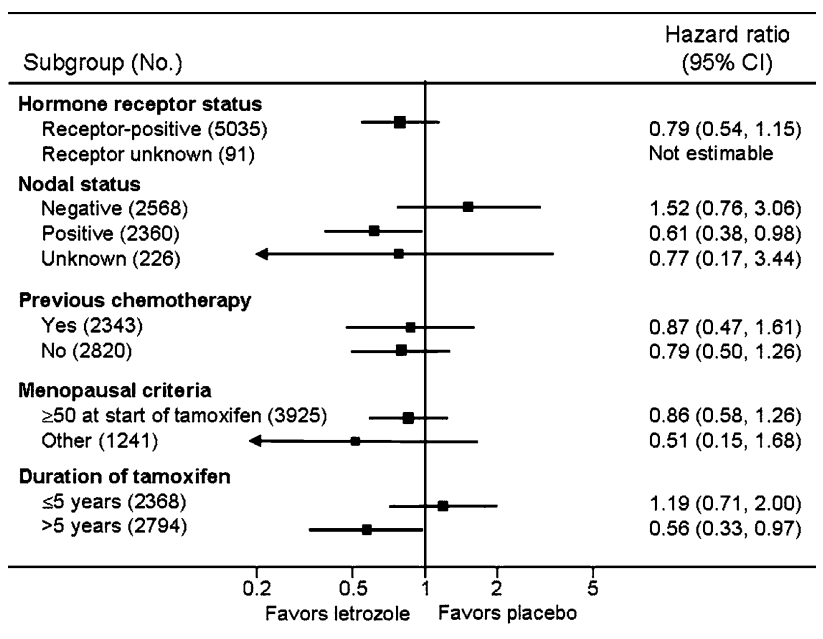

Fig. 3 Forest plots of the treatment effect (letrozole vs. placebo), in terms of overall survival, in subgroups defined by hormone receptor status, lymph node status, previous chemotherapy, menopausal criteria, and duration of tamoxifen treatment. For each subgroup, the hazard ratio for death from any cause is plotted as a solid square, and the area of the square is proportional to the variance of the estimated effect. The length of the horizontal line through the square indicates the $95 \%$ confidence interval (CI). The arrow at the end of the horizontal line indicates that the confidence interval is larger than the scale of the figure. Reprinted from ref. [29] with permission

\section{Additional MA.17 analyses}

Optimal duration of extended adjuvant letrozole

The final MA.17 database, including all events up to the date of unblinding, was analyzed to examine the relationship between duration of treatment and outcomes [38, 39]. Data from this analysis have provided further evidence to support an extended duration of letrozole, as this cohort analysis found that the longer patients are exposed to extended adjuvant letrozole (at least out to 48 months), the greater the benefit [39].

The risk of disease recurrence increased over time in the placebo group, whereas in patients receiving letrozole, risk appeared to peak at around 2 years of treatment and decrease thereafter. In the overall patient population, hazard ratios for events in DFS and DDFS progressively decreased over time, favoring letrozole, with the trend being significant $(P<0.0001$ and $P=0.0013$, respectively). The trend for OS was not significant but was always $<1$. In the 2,360 patients with node-positive status, hazard ratios for DFS, DDFS, and OS all decreased over time, with tests for trend all showing significance $(P=0.0004,0.0005$, and 0.038 , respectively). Considering the 2,568 patients with nodenegative status, the hazard ratios for DFS decreased over time, with the test for trend being significant $(P=0.027)$, whereas the hazard ratios for DDFS and OS showed no significant change over time (see Table 1). 
Table 1 Analysis of the hazard ratios for disease recurrence over time between the letrozole and placebo arms of MA.17

Reprinted from ref. [38] with permission from Elsevier

${ }^{\text {a }}$ Hazard ratios $<1$ indicate values in favor of letrozole

\begin{tabular}{|c|c|c|c|c|}
\hline $\begin{array}{l}\text { Month after } \\
\text { randomization }\end{array}$ & $\begin{array}{l}\text { No. at risk (letrozole/ } \\
\text { placebo) }\end{array}$ & $\begin{array}{ll}\text { Hazard } & \text { rate } \\
\text { (letrozole) } & \end{array}$ & $\begin{array}{l}\text { Hazard } \\
\text { (placebo) }\end{array}$ & $\begin{array}{l}\text { Hazard ratio (letrozole vs } \\
\text { placebo) }{ }^{\mathrm{a}}\end{array}$ \\
\hline 12 & $2,425 / 2,409$ & 0.00093 & 0.00180 & $0.52(0.40-0.64)$ \\
\hline 24 & $1,555 / 1,530$ & 0.00105 & 0.00236 & $0.45(0.33-0.56)$ \\
\hline 36 & $768 / 723$ & 0.00090 & 0.00261 & $0.35(0.21-0.48)$ \\
\hline 48 & $244 / 231$ & 0.00059 & 0.00306 & $0.19(0.04,0.34)$ \\
\hline
\end{tabular}

\section{MA.17 ITT analysis}

The intent-to-treat (ITT) analysis at 54 months' follow-up looked at all outcomes, including all events before and after the unblinding, based on the original randomization of letrozole versus placebo; it did not take into account whether or not patients in the placebo group switched to letrozole at the unblinding of the data. The results further showed that patients randomized initially to letrozole had fewer DFS events than those initially randomized to placebo [40]. Publication of the final analysis of this data are awaited, but these provisional results highlight the strong beneficial effect of extended adjuvant therapy with letrozole when started immediately after tamoxifen.

Impact of HR status on clinical benefit

A retrospective analysis was conducted to determine whether HR status had an effect on the outcome of letrozole in the extended adjuvant setting [41]. ER and PgR positivity were defined as $\geq 10 \mathrm{fmol} / \mathrm{mg}$ protein or positive by immunocytochemical analysis. Preliminary results from 4,635 patients, based on local testing of HR status, showed that the reduction in risk of recurrence with letrozole compared with placebo was greatest in women with the most hormone-dependent tumors. The final results of this analysis await publication. These results should be interpreted cautiously, as this was an unplanned, retrospective analysis, and receptor levels were measured locally. Furthermore, from the outset, the analysis of outcomes in all other subgroups besides the ER+/PgR+ $(n=3,809)$ patients was weakened by the low numbers of patients in these groups (e.g., ER+/PgR-, $n=636$ ) [42].

\section{MA.17 post-unblinding analysis}

The trial was unblinded in 2003 because DFS values were met (stopping boundary nominal significance, $P=0.0008$ ) and patients were given the opportunity to cross over. Postunblinding analysis of MA.17 has provided additional efficacy data on patients who had crossed over from placebo to letrozole $(n=1,655)$, comparing them with patients who elected no treatment at the time of the unblinding $(n=613)$ [43]. These patients had not received any hormonal therapy after discontinuing tamoxifen. Data were adjusted for baseline patient and disease variables including tumor size, nodal status, and prior adjuvant chemotherapy. A preliminary analysis suggests that letrozole has significant clinical benefits in patients in whom treatment with the AI is started after a prolonged period since the discontinuation of tamoxifen. The publication of these results is eagerly awaited as they may effect patient care worldwide.

\section{MA.17 re-randomization}

A re-randomization of all patients completing letrozole to receive a further 5 years of letrozole or placebo is under way to confirm this finding [40,44]. An amendment to this protocol allows women completing 5 years of any AI to be re-randomized to a further 5 years of letrozole or not regardless of prior tamoxifen or its duration. The MA.17 re-randomization study should provide additional insights into the efficacy and safety of extending letrozole therapy beyond 5 years [45].

\section{Safety of letrozole in the extended adjuvant setting}

The women included in this trial had been disease-free for approximately 5 years during treatment with tamoxifen and, therefore, the safety and tolerability of continued hormone treatment with letrozole was an important consideration when the MA.17 trial was designed. Furthermore, early unblinding of the trial has not prevented the collection of long-term safety data, and additional substudies are providing useful information on the safety profile of letrozole in the extended adjuvant setting. The safety of AIs is discussed in detail in the paper by Dr. Perez in this supplement.

The MA.17 trial showed that letrozole is extremely well tolerated relative to placebo. The most common adverse events reported were secondary to estrogen suppression and included hot flashes, myalgia, arthralgia, alopecia, and newly diagnosed osteoporosis. The increase in newly 
diagnosed osteoporosis $(8.1 \%$ for letrozole vs. $6 \%$ for placebo; $P=0.003$ ) [29] was predictable from the potent suppression of estrogens by third-generation AIs [17] and the association between estrogen levels and bone turnover [46-48]. Of note, no significant difference in clinical fracture rate was seen between letrozole and placebo groups (5.3 vs. $4.6 \% ; P=0.25$ ) [29].

MA.17B is a companion study designed to compare the effects of letrozole $(n=122)$ and placebo $(n=104)$ on BMD in the L2-L4 (posteroanterior) region of the spine and hip [35]. At 24 months, patients receiving letrozole had a significant decrease in total hip BMD ( -3.6 vs $-0.71 \% ; P=0.044)$ and lumbar spine BMD ( -5.35 vs. $-0.70 \% ; P=0.008$ ). Further follow-up is necessary to evaluate the long-term clinical implications of this modest increase in bone resorption and reduction in BMD in the spine and hip with letrozole compared with placebo. Prophylactic use of the bisphosphonate zoledronic acid is being studied as a means to prevent BMD loss [49, 50]. Results from two clinical trials have indicated that early use of zoledronic acid effectively prevents BMD loss in women receiving adjuvant letrozole [49, 51].

Estrogen has a beneficial effect on lipid profiles, and it has been suggested that AIs may have a relatively unfavorable effect. However, MA.17L, a substudy of MA.17 $(n=347)$, demonstrated that letrozole does not significantly alter serum cholesterol, high-density lipoprotein cholesterol, low-density lipoprotein cholesterol, triglycerides, or lipoprotein (a) compared with placebo [34]. This is in agreement with the results of the main MA.17 trial, which showed no difference in hypercholesterolemia rates between placebo and letrozole [28]. Importantly, in the updated analysis of the MA.17 dataset, there were no significant differences between the letrozole and placebo arms in the incidence of hypercholesterolemia $(16 \%$ in each arm; $P=0.79$ ) or cardiovascular events (5.8 vs. $5.6 \%$; $P=0.76)$ [29].

The QOL substudy was conducted in 3,612 patients treated in MA.17 (1,813 letrozole and 1,799 placebo) [31]. The analysis demonstrated that letrozole did not have an adverse impact on overall QOL, as determined by SF-36, which is an important and reassuring finding, as the extension of letrozole treatment for up to 10 years in this setting is now being tested [44].

\section{Conclusions}

In recent years, considerable progress has been made in developing more effective hormonal treatments for women with breast cancer and improving the efficacy demonstrated with tamoxifen [3]. The pioneering MA.17 trial has demonstrated the need for extended adjuvant therapy after
5 years of tamoxifen to reduce the risk of recurrence in postmenopausal women with HR+ breast cancer. On the basis of this trial, letrozole was approved as extended adjuvant therapy, and it is currently the only AI approved for this indication [22, 52].

MA.17 demonstrated that extended adjuvant therapy with letrozole provides women further protection against relapse after the completion of tamoxifen. These findings support the concept that distant micrometastases that have survived 5 years of tamoxifen therapy remain highly estrogen-sensitive and responsive to extended adjuvant letrozole treatment. This is an important clinical benefit in view of the persistent risk of relapse beyond 10 years in patients with HR+ tumors [4]. In fact, the cohort analysis showed that in the placebo group, there was actually an increasing risk of disease recurrence over time after discontinuing prior tamoxifen [40]. The preliminary MA.17 ITT data suggest that the strongest beneficial effect is still obtained when starting letrozole within 3 months of completing tamoxifen [38], while the post-unblinding results suggest that women with hormone-dependent breast cancer who are prescribed letrozole following a prolonged delay after completing tamoxifen may experience a significant improvement in outcome [43]. Therefore, if a patient misses the chance to start letrozole within 3 months post tamoxifen, these results suggest that there is still a benefit to initiating letrozole therapy for up to 5 years following the discontinuation of tamoxifen. Importantly, women in all risk categories benefited in terms of reduced risk for recurrence of their cancer. Thus, in both node-positive as well as node-negative women, there was a strong improvement in DFS, and "low risk" status of the primary tumor should not preclude consideration of extended adjuvant therapy with letrozole. Extended therapy with adjuvant letrozole should therefore be considered for all women currently completing tamoxifen. In addition, in women who have completed tamoxifen within the last 5 years, introduction of letrozole for 5 years can be discussed because although we do not have level 1 evidence for benefit in this setting as yet, our post-unblinding analysis of MA17 strongly supports the potential for benefit in these women.

Among the clinical questions left unanswered are the optimal duration of letrozole and the long-term safety of extended adjuvant therapy in women leading a normal healthy lifestyle. Preliminary results of a cohort study analysis of MA.17 provide support for the use of extended adjuvant letrozole for at least up to 4 years [40, 53]. The MA-17 re-randomization study will assign patients completing 5 years of letrozole to a further 5 years of letrozole or placebo and should provide data on the efficacy and safety of extending letrozole therapy beyond 5 years [45].

In conclusion, HR+ breast cancer presents an unremitting threat that may require life-long hormone therapy. The 
optimal hormone treatment strategy is evolving based on the results of landmark clinical trials in the initial adjuvant [54, 55], sequential adjuvant [56], and extended adjuvant settings $[28,29]$. The optimal agent, sequence of treatments, or combination of treatments will be able to provide the greatest improvement in OS with minimal acute and long-term toxicity. MA.17 has demonstrated that letrozole is highly effective and extremely well tolerated when given in the extended adjuvant setting. The results of the pivotal MA.17 trial have changed current clinical practice to extend letrozole protective therapy in thousands of breast cancer patients currently receiving 5 years of adjuvant tamoxifen. The benefits of long-term adjuvant letrozole treatment clearly outweigh any adverse events in postmenopausal women who have survived breast cancer after initial adjuvant therapy with tamoxifen. Long-term side effects and risks continue to be monitored and taken into account when any individual patient is being considered for extended adjuvant therapy.

\section{References}

1. Early Breast Cancer Trialists' Collaborative Group (1992) Systemic treatment of early breast cancer by hormonal, cytotoxic, or immune therapy. Lancet 339:1-15

2. Early Breast Cancer Trialists' Collaborative Group (1998) Tamoxifen for early breast cancer: an overview of the randomised trials. Lancet 351:1451-1467

3. Early Breast Cancer Trialists' Collaborative Group (EBCTCG) (2005) Effects of chemotherapy and hormonal therapy for early breast cancer on recurrence and 15-year survival: an overview of the randomised trials. Lancet 365:1687-1717

4. Saphner T, Tormey DC, Gray R (1996) Annual hazard rates of recurrence for breast cancer after primary therapy. J Clin Oncol 14:2738-2746

5. Fisher B, Costantino J, Redmond C, Poisson R, Bowman D, Couture J, Dimitrov NV, Wolmark N, Wickerham DL, Fisher ER et al (1989) A randomized clinical trial evaluating tamoxifen in the treatment of patients with node-negative breast cancer who have estrogen-receptor-positive tumors. N Engl J Med 320:479-484

6. Fisher B, Dignam J, Bryant J, DeCillis A, Wickerham DL, Wolmark N, Costantino J, Redmond C, Fisher ER, Bowman DM, Deschenes L, Dimitrov NV, Margolese RG, Robidoux A, Shibata H, Terz J, Paterson AH, Feldman MI, Farrar W, Evans J, Lickley HL (1996) Five versus more than five years of tamoxifen therapy for breast cancer patients with negative lymph nodes and estrogen receptor-positive tumors. J Natl Cancer Inst 88:1529-1542

7. Fisher B, Dignam J, Bryant J, Wolmark N (2001) Five versus more than five years of tamoxifen for lymph node-negative breast cancer: updated findings from the National Surgical Adjuvant Breast and Bowel Project B-14 randomized trial. J Natl Cancer Inst 93:684-690

8. National Cancer Institute (1995) Clinical announcement: adjuvant therapy of breast cancer - tamoxifen update. Bethesda (MD) National Institutes of Health

9. Jeng MH, Yue W, Eischeid A, Wang JP, Santen RJ (2000) Role of MAP kinase in the enhanced cell proliferation of long term estrogen deprived human breast cancer cells. Breast Cancer Res Treat 62:167-175
10. Shou J, Massarweh S, Osborne CK, Wakeling AE, Ali S, Weiss H, Schiff R (2004) Mechanisms of tamoxifen resistance: increased estrogen receptor-HER2/neu cross-talk in ER/HER2positive breast cancer. J Natl Cancer Inst 96:926-935

11. Yue W, Wang JP, Conaway M, Masamura S, Li Y, Santen RJ (2002) Activation of the MAPK pathway enhances sensitivity of MCF-7 breast cancer cells to the mitogenic effect of estradiol. Endocrinology 143:3221-3229

12. Berstein LM, Wang JP, Zheng H, Yue W, Conaway M, Santen RJ (2004) Long-term exposure to tamoxifen induces hypersensitivity to estradiol. Clin Cancer Res 10:1530-1534

13. Mamounas EP (2001) Adjuvant exemestane therapy after 5 years of tamoxifen: rationale for the NSABP B-33 trial. Oncology (Williston Park) 15(5 Suppl 7):35-39

14. Bhatnagar AS, Hausler A, Schieweck K, Lang M, Bowman R (1990) Highly selective inhibition of estrogen biosynthesis by CGS 20267, a new non-steroidal aromatase inhibitor. J Steroid Biochem Mol Biol 37:1021-1027

15. Plourde PV, Dyroff M, Dukes M (1994) Arimidex: a potent and selective fourth-generation aromatase inhibitor. Breast Cancer Res Treat 30:103-111

16. Giudici D, Ornati G, Briatico G, Buzzetti F, Lombardi P, di Salle E (1988) 6-Methylenandrosta-1,4-diene-3,17-dione (FCE 24304): a new irreversible aromatase inhibitor. J Steroid Biochem 30:391-394

17. Bhatnager AS, Brodie AMH, Long BJ, Evans DB, Miller WR (2001) Intracellular aromatase and its relevance to the pharmacological efficacy of aromatase inhibitors. J Steroid Biochem Mol Biol 76:199-202

18. Geisler J, Haynes B, Anker G, Dowsett M, Lonning PE (2002) Influence of letrozole and anastrozole on total body aromatization and plasma estrogen levels in postmenopausal breast cancer women evaluated in a randomized, cross-over study. J Clin Oncol 20:751-757

19. Dixon JM, Renshaw L, Young O, Murray J, Macaskill J, McHugh M, Folkerd E, Cameron D, Dowsett M (2006) Letrozole suppresses plasma oestradiol (E2) levels more completely than anastrozole in postmenopausal women with breast cancer. Ann Oncol 17:ix93-ix113, Abstract 265P

20. Mouridsen H, Gershanovich M, Sun Y, Perez-Carrion R, Boni C, Monnier A, Apffelstaedt J, Smith R, Sleeboom HP, Janicke F, Pluzanska A, Dank M, Becquart D, Bapsy PP, Salminen E, Snyder R, Lassus M, Verbeek JA, Staffler B, Chaudri-Ross HA, Dugan M (2001) Superior efficacy of letrozole versus tamoxifen as first-line therapy for postmenopausal women with advanced breast cancer: results of a phase III study of the International Letrozole Breast Cancer Group. J Clin Oncol 19:2596-2606. Erratum in: J Clin Oncol (2001) 19:3302

21. Mouridsen H, Gershanovich M, Sun Y, Perez-Carrion R, Boni C, Monnier A, Apffelstaedt J, Smith R, Sleeboom HP, Jaenicke F, Pluzanska A, Dank M, Becquart D, Bapsy PP, Salminen E, Snyder R, Chaudri-Ross H, Lang R, Wyld P, Bhatnagar A (2003) Phase III study of letrozole versus tamoxifen as first-line therapy of advanced breast cancer in postmenopausal women: analysis of survival and update of efficacy from the International Letrozole Breast Cancer Group. J Clin Oncol 21:2101-2109

22. Femara package insert. East Hanover, NJ; Novartis Pharmaceuticals Corp. (2005)

23. Dombernowsky P, Smith I, Falkson G, Leonard R, Panasci L, Bellmunt J, Bezwoda W, Gardin G, Gudgeon A, Morgan M, Fornasiero A, Hoffmann W, Michel J, Hatschek T, Tjabbes T, Chaudri HA, Hornberger U, Trunet PF (1998) Letrozole, a new oral aromatase inhibitor for advanced breast cancer: double-blind randomized trial showing a dose effect and improved efficacy and tolerability compared with megestrol acetate. J Clin Oncol $16: 453-461$ 
24. Rose C, Vtoraya O, Pluzanska A, Davidson N, Gershanovich M, Thomas R, Johnson S, Caicedo JJ, Gervasio H, Manikhas G, Ben Ayed F, Burdette-Radoux S, Chaudri-Ross HA, Lang R (2003) An open randomised trial of second-line endocrine therapy in advanced breast cancer: comparison of the aromatase inhibitors letrozole and anastrozole. Eur J Cancer 39:2318-2327

25. Brodie A, Lu Q, Liu Y, Long B (1999) Aromatase inhibitors and their antitumor effects in model systems. Endocr Relat Cancer 6:205-210

26. Lu Q, Yue W, Wang J, Liu Y, Long B, Brodie A (1998) The effects of aromatase inhibitors and antiestrogens in the nude mouse model. Breast Cancer Res Treat 50:63-71

27. Long BJ, Jelovac D, Handratta V, Thiantanawat A, MacPherson N, Ragaz J, Goloubeva OG, Brodie AM (2004) Therapeutic strategies using the aromatase inhibitor letrozole and tamoxifen in a breast cancer model. J Natl Cancer Inst 96:456-465

28. Goss PE, Ingle JN, Martino S, Robert NJ, Muss HB, Piccart MJ, Castiglione M, Tu D, Shepherd LE, Pritchard KI, Livingston RB, Davidson NE, Norton L, Perez EA, Abrams JS, Therasse P, Palmer MJ, Pater JL (2003) A randomized trial of letrozole in postmenopausal women after five years of tamoxifen therapy for early-stage breast cancer. N Engl J Med 349:1793-1802

29. Goss PE, Ingle JN, Martino S, Robert NJ, Muss HB, Piccart MJ, Castiglione M, Tu D, Shepherd LE, Pritchard KI, Livingston RB, Davidson NE, Norton L, Perez EA, Abrams JS, Cameron DA, Palmer MJ, Pater JL (2005) Randomized trial of letrozole following tamoxifen as extended adjuvant therapy in receptorpositive breast cancer: updated findings from NCIC CTG MA.17. J Natl Cancer Inst 97:1262-1271

30. Lan G, DeMets D (1983) Discrete sequential boundaries for clinical trials. Biometrika 70:659-663

31. Whelan TJ, Goss PE, Ingle JN, Pater JL, Tu D, Pritchard K, Liu S, Shepherd LE, Palmer M, Robert NJ, Martino S, Muss HB (2005) Assessment of quality of life in MA.17: a randomized, placebo-controlled trial of letrozole after 5 years of tamoxifen in postmenopausal women. J Clin Oncol 23:6931-6940

32. Ware JE Jr, Sherbourne CD (1992) The MOS 36-item short-form health survey (SF-36). I. Conceptual framework and item selection. Med Care 30:473-483

33. Hilditch JR, Lewis J, Peter A, van Maris B, Ross A, Franssen E, Guyatt GH, Norton PG, Dunn E (1996) A menopause-specific quality of life questionnaire: development and psychometric properties. Maturitas 24:161-175. Erratum in: Maturitas (1996) 25:231

34. Wasan KM, Goss PE, Pritchard PH, Shepherd L, Palmer MJ, Liu S, Tu D, Ingle JN, Heath M, Deangelis D, Perez EA (2005) The influence of letrozole on serum lipid concentrations in postmenopausal women with primary breast cancer who have completed 5 years of adjuvant tamoxifen (NCIC CTG MA.17L). Ann Oncol $16: 707-715$

35. Perez EA, Josse RG, Pritchard KI, Ingle JN, Martino S, Findlay BP, Shenkier TN, Tozer RG, Palmer MJ, Shepherd LE, Liu S, Tu D, Goss PE (2006) Effect of letrozole versus placebo on bone mineral density in women with primary breast cancer completing 5 or more years of adjuvant tamoxifen: a companion study to NCIC CTG MA.17. J Clin Oncol 24:3629-3635

36. Bryant J, Wolmark N (2003) Letrozole after tamoxifen for breast cancer - what is the price of success? N Engl J Med 349:18551857

37. Lamerato L, Havstad S, Gandhi S, Jones D, Chlebowski R (2005) Breast cancer recurrence and related mortality in US pts with early breast cancer. J Clin Oncol 25(suppl 16):62s. Abstract 738

38. Ingle J, Goss P, Dongsheng T (2005) NCIC CTG MA 17: Increasing benefit of letrozole with longer duration of treatment as measured by the hazard ratio of disease recurrence over time. Eur J Cancer Suppl 3:74. Abstract 266
39. Ingle JN, Tu D, Pater JL, Martino S, Robert NJ, Muss HB, Piccart MJ, Castiglione M, Shepherd LE, Pritchard KI, Livingston RB, Davidson NE, Norton L, Perez EA, Abrams JS, Cameron DA, Palmer MJ, Goss PE (2006) Duration of letrozole treatment and outcomes in the placebo-controlled NCIC CTG MA.17 extended adjuvant therapy trial. Breast Cancer Res Treat 99:295-300

40. Ingle J, Tu D, Shepherd L, Palmer M, Pater J, Goss P (2006) NCIC CTG MA.17: intent to treat analysis (ITT) of randomized patients after a median follow-up of 54 months. J Clin Oncol 24(18S):15s. Abstract 549

41. Goss PE, Ingle JN, Tu D (2005) NCIC CTG MA17: disease free survival according to estrogen receptor and progesterone receptor status of the primary tumor. Breast Cancer Res Treat 94(suppl 1):S98. Abstract 2042

42. Goss P, Ingle J, Tu D, on behalf of the Ma.17 Collaborative Trialists (2006) NCIC CTG MA17: updated analysis on disease free survival (DFS) according to estrogen receptor and progesterone receptor status of the primary tumor. Eur J Cancer Suppl 4(2):149. Abstract 350

43. Robert NJ, Goss PE, Ingle JN, Tu D, Shepherd L, Palmer M, Pater J (2006) Updated analysis of NCIC CTG MA.17 (letrozole vs. placebo to letrozole vs. placebo post unblinding. J Clin Oncol 24(18S):15s. Abstract 550

44. Pritchard KI, Goss PE, Shepherd L (2006) The extended adjuvant NCIC CTG MA.17 trials: initial and rerandomization studies. Breast 15(1 suppl):14-20

45. Goss PE, Ingle JN, Palmer MJ, Shepherd LE, Tu D (2005) Updated analysis of NCIC CTG MA.17 (letrozole vs. placebo to letrozole vs placebo) post unblinding. Breast Cancer Res Treat 94(suppl 1):S10. Abstract 16

46. Chapurlat RD, Bauer DC, Cummings SR (2001) Association between endogenous hormones and sex hormone-binding globulin and bone turnover in older women: study of osteoporotic fractures. Bone 29:381-387

47. Heshmati HM, Khosla S, Robins SP, O'Fallon WM, Melton LJ 3rd, Riggs BL (2002) Role of low levels of endogenous estrogen in regulation of bone resorption in late postmenopausal women. $\mathrm{J}$ Bone Miner Res 17:172-178

48. Gao Y, Qian WP, Dark K, Toraldo G, Lin AS, Guldberg RE, Flavell RA, Weitzmann MN, Pacifici R (2004) Estrogen prevents bone loss through transforming growth factor beta signalling in $\mathrm{T}$ cells. Proc Natl Acad Sci USA 101:16618-16623

49. Brufsky A, Harker WG, Beck JT, Carroll R, Tan-Chiu E, Seidler C, Hohneker J, Lacerna L, Petrone S, Perez EA (2007) Zoledronic acid inhibits adjuvant letrozole-induced bone loss in postmenopausal women with early breast cancer J Clin Oncol 25:829-836

50. Gnant M, Jakesz R, Mlineritsch B, Luschin-Ebengreuth G, Schmid M, Menzel C, Kubista E, Samonigg H, Hausmaninger $\mathrm{H}$, the ABCSG (2004) Zoledronic acid effectively counteracts cancer treatment induced bone loss (CTIBL) in premenopausal breast cancer patients receiving adjuvant endocrine treatment with goserelin plus anastrozole versus goserelin plus tamoxifen - bone density subprotocol results of a randomized multicenter trial (ABCSG-12). Presented at the 27th Annual San Antonio Breast Cancer Symposium, 8-11 December 2004. Abstract 6

51. Bundred N, Campbell I, Coleman R, DeBoer R, Eidtmann H, Frassolati A, Llombart A, Monnier A, Neven P, Dias R (2006) Zoledronic acid in the prevention of cancer treatment-induced bone loss in postmenopausal women receiving letrozole as adjuvant therapy for early breast cancer (ZOFAST study). Eur J Cancer Suppl 4(2):48

52. Mann BS, Johnson JR, Kelly R, Sridhara R, Williams G, Pazdur $R$ (2005) Letrozole in the extended adjuvant treatment of postmenopausal women with history of early-stage breast cancer who 
have completed 5 years of adjuvant tamoxifen. Clin Cancer Res 11:5671-5677

53. Winer EP, Hudis C, Burstein HJ, Wolff AC, Pritchard KI, Ingle JN, Chlebowski RT, Gelber R, Edge SB, Gralow J, Cobleigh MA, Mamounas EP, Goldstein LJ, Whelan TJ, Powles TJ, Bryant J, Perkins C, Perotti J, Braun S, Langer AS, Browman GP, Somerfield MR (2005) American Society of Clinical Oncology technology assessment on the use of aromatase inhibitors as adjuvant therapy for postmenopausal women with hormone receptor-positive breast cancer: status report 2004. J Clin Oncol 23:619-629

54. Thurlimann B, Keshaviah A, Coates AS, Mouridsen H, Mauriac L, Forbes JF, Paridaens R, Castiglione-Gertsch M, Gelber RD, Rabaglio M, Smith I, Wardley A, Price KN, Goldhirsch A, Breast
International Group (BIG) 1-98 Collaborative Group (2005) A comparison of letrozole and tamoxifen in postmenopausal women with early breast cancer. N Engl J Med 353:2747-2757

55. Howell A, Cuzick J, Baum M, Buzdar A, Dowsett M, Forbes JF, Hoctin-Boes G, Houghton J, Locker GY, Tobias JS, ATAC Trialists' Group (2005) Results of the ATAC (Arimidex, Tamoxifen, Alone or in Combination) trial after completion of 5 years' adjuvant treatment for breast cancer. Lancet 365: $60-62$

56. Coombes RC, Paridaens R, Jassem J, Van de Velde CJ, Delozier T, Jones SE, Hall E, Kilburn LS, Snowdon CF, Bliss JM, for the Intergroup Exemestane Study (IES) (2006) First mature analysis of the Intergroup Exemestane Study. J Clin Oncol 24(18S):933s. Abstract LBA527 